\title{
NVP-BEZ235 overcomes gefitinib-acquired resistance by down-regulating PI3K/AKT/ mTOR phosphorylation
}

This article was published in the following Dove Press journal:

OncoTargets and Therapy

29 January 2015

Number of times this article has been viewed

\section{Zhihua Sun ${ }^{2, *}$ \\ Qiuhui $\mid i^{1, *}$ \\ Sheng Zhang' \\ Jing Chen' \\ Lili Huang ${ }^{3}$ \\ Jinghua Ren' \\ Yu Chang' \\ Yichen Liang' \\ Gang Wu'}

'Cancer Center, Union Hospital, Tongji Medical College, Huazhong University of Science and Technology, Wuhan, Hubei, People's Republic of China; ${ }^{2}$ Oncology department, Xiangyang central Hospital, Xiangyang, Hubei, People's Republic of China; ${ }^{3}$ Radiation Oncology Department, Fifth Affiliated Hospital of Sun Yat-sen University, Zhuhai, Guangdong, People's Republic of China

*These authors contributed equally to this work
Correspondence: Gang Wu I56 WujiaDun, JiangHan District, Wuhan, Hubei, People's Republic of China Tel +86 2765650086

Fax +86 2765650733

Email wugangxhzl@I63.com
Background: Patients harboring activating mutations in epidermal growth factor receptors (EGFR) are particularly sensitive to EGFR tyrosine kinase inhibitors (TKIs). However, most patients develop an acquired resistance after a period of about 10 months. This study focuses on the therapeutic effect of NVP-BEZ235, a dual inhibitor of phosphatidylinositol3-kinase/mammalian target of rapamycin (PI3K/mTOR), in gefitinib-resistant non-small cell lung cancer.

Methods: H1975 cell line was validated as a gefitinib-resistant cell model by the nucleotidesequence analysis. We used the 3-(4,5-Dimethylthiazol-2-yl)-2,5-diphenyltetrazolium bromide (MTT) assay to detect the growth of H1975 cell line in vitro. H1975 cells' migration was detected by the migration assay. Xenograft models were used to investigate the growth of gefitinib-resistant non-small cell lung cancer in vivo. Western blot and immunohistochemical analysis were used to investigate the level of PI3K/protein kinase $\mathrm{B}(\mathrm{AKT}) / \mathrm{mTOR}$ signaling pathway proteins.

Results: We show that NVP-BEZ235 effectively inhibited the growth of H1975 cells in vivo as well as in vitro. Similarly, H1975 cell migration was reduced by NVP-BEZ235. Further experiments revealed that NVP-BEZ235 attenuated the phosphorylation of PI3K/AKT/mTOR signaling pathway proteins.

Conclusion: Taken together, we suggest that NVP-BEZ235 inhibits gefitinib-resistant tumor growth by downregulating PI3K/AKT/mTOR phosphorylation.

Keywords: gefitinib-acquired resistance, PI3K kinase, mTOR, NVP-BEZ235

\section{Introduction}

Advanced non-small cell lung cancer (NSCLC) is the leading cause of cancer-related death worldwide. ${ }^{1}$ The epidermal growth factor receptor (EGFR) tyrosine kinase inhibitors (TKIs), gefitinib (Iressa ${ }^{\circledR}$; AstraZeneca, London, UK) and erlotinib, competitively bind with the active site of the EGFR kinase. A subgroup of patients with activating mutations in EGFR are particularly sensitive to EGFR TKIs. ${ }^{2,3}$ Exon 19 deletion mutations and the single-point substitution mutation L858R in exon 21 are the most prevalent among these activating mutations. ${ }^{4}$ However, after a period of about 10 months of progression-free survival, most patients relapse because of the development of an acquired resistance to EGFR TKIs. ${ }^{5}$ Further research exhibited that the secondary threonine-to-methionine substitution at codon 790(T790M) accounts for approximately half of the cases of the acquired resistance. ${ }^{6,7}$ A bulkier amino acid is introduced by the methionine substitution to the acetylene side chain and this alteration makes a steric hindrance that may interfere with the binding of EGFR TKIs, eventually leading to 
the development of EGFR TKIs resistance. ${ }^{7}$ Approximately another $20 \%-25 \%$ of EGFR TKIs resistance arises due to the amplification of mesenchymal-epidermal transition (MET), another tyrosine kinase receptor. ${ }^{8,9}$ The MET amplification results in continuous activation of the phosphatidylinositol3-kinase (PI3K)/protein kinase B (AKT) and MEK-ERK signaling pathway despite EGFR inhibition. Moreover, MET inhibitors re-sensitize these cancers to EGFR TKIs. ${ }^{9,10}$ The T790M mutation and proto-oncogene MET amplification, both of which are independent resistance mechanisms, as suggested by Bean et al, ${ }^{9}$ tend to cause sustained activation of the PI3K-AKT-mammalian target of rapamycin (mTOR) signaling pathway.

It has been recognized that abnormal activation of the $\mathrm{PI} 3 \mathrm{~K} / \mathrm{AKT} / \mathrm{mTOR}$ signaling pathway is implicated with human cancer. ${ }^{11} \mathrm{PI} 3 \mathrm{~K}$ is a heterodimer comprised of a p85 regulatory and a p110 catalytic subunit. Once PI3K is activated, p110 phosphorylates the phosphatidylinositol4,5-diphosphate(PIP2) to phosphatidylinositol-3,4,5triphosphate(PIP3), which facilitates the phosphorylation of AKT at Thr308 by PDK $1 .{ }^{12}$ A second phosphorylation event at Ser473 by the mTOR-rictor complex is required for maximal AKT activity. ${ }^{13}$ The downstream target of PI3K/AKT pathway, mTOR, a serine/threonine-specific protein kinase, phosphorylates S6 ribosomal protein, and eukaryotic initiation factor $4 \mathrm{E}$ binding protein 1 , thereby regulating tumor cell growth and proliferation. NVP-BEZ235, which directly targets the PI3K-AKT-mTOR pathway, has been found to have potential application in clinical practice. ${ }^{14}$ BEZ235 is an imidazo[4,5-c] quinoline derivative that inhibits PI3K and the downstream mTOR kinase activity by binding to the ATP-binding cleft of these enzymes. Moreover, BEZ235 inhibits the activation of the downstream effectors AKT, S6 ribosomal protein, and 4E binding protein 1 in breast cancer cells. ${ }^{14-16}$ Therefore, we hypothesized that blocking the common downstream PI3K-AKT-mTOR signaling pathway by BEZ235 may be an effective approach to overcome the EGFR TKIs resistance.

In this study, NCI-H1975 cell line, which harbors both T790M and L858R mutations in EGFR, was used as a model of gefitinib-acquired resistance to examine the inhibitory effect of NVP-BEZ235 on gefitinib-resistant tumors in vitro as well as in vivo.

\section{Materials and methods}

\section{Cell line and culture conditions}

H1975 cell line was obtained from the American Type Culture Collection (ATCC, Manassas, VA, USA) and maintained in Dulbecco's Modified Eagle's Medium (HyClone) supplemented with $10 \%$ fetal bovine serum (HyClone) at $37^{\circ} \mathrm{C}$ in $5 \% \mathrm{CO}_{2}$.

\section{Reagents}

NVP-BEZ235 was purchased from Selleck Chemicals (Houston, TX, USA), dissolved in dimethyl sulfoxide (DMSO) (Amresco LLC, Solon, OH, USA) to $10 \mathrm{mmol} / \mathrm{L}$. Gefitinib was kindly supplied by AstraZeneca and dissolved in DMSO to the concentration of $25 \mathrm{mmol} / \mathrm{L}$. Both compounds were stored at $-20^{\circ} \mathrm{C}$, and further diluted to the needed concentration in Dulbecco's Modified Eagle's Medium. DMSO was added to the culture medium of the control cells and was constantly kept below $0.1 \%$. Antibodies against Ser473-phospho-AKT(9271), Ser235/236-phosphoS6(2211), and ribosomal protein S6(2217) were procured from Cell Signaling Technology (Danvers, MA, USA). AKT was bought from Proteintech Group, Inc. (Chicago, IL, USA) and $\beta$-actin was from Santa Cruz Biotechnology Inc. (Dallas, TX, USA).

\section{Cell growth assay}

The 3-(4,5-Dimethylthiazol-2-yl)-2,5-diphenyltetrazolium bromide (MTT) method was employed to estimate the number of viable cells by following the manufacturer's instructions (Sigma-Aldrich Co, St Louis, MO, USA ). Briefly, H1975 cells were grown in $200 \mu \mathrm{L}$ medium at $37^{\circ} \mathrm{C}$ in $5 \% \mathrm{CO}_{2}$ for 72 hours in 96-well plates, and then incubated with $20 \mu \mathrm{L}$ MTT $(5 \mathrm{~g} / \mathrm{L})$ for 4 hours. Afterwards, $150 \mu \mathrm{L}$ DMSO was added to each well, and the absorbance value at $490 \mathrm{~nm}$ was read on a Microplate reader (Eppendorf, Hamburg, Germany).

\section{Nucleotide sequencing of EGFR DNA of HI 975 cells}

For detection of the given mutation in the EGFR coding sequence, DNA was extracted from H1975 cells, and all 18-21 exons were amplified by polymerase chain reaction with the primers being as follows: forward, 5'-TGAAGGCTGTCCAACGA-3'; reverse, 5'-TTCCAATGCCATCCACT- ${ }^{\prime}$. The products were directly sequenced in both sense and anti-sense directions by Invitrogen (Thermo Fisher Scientific, Waltham, MA, USA).

\section{Migration assay}

H1975 cells migration upon treatment with BEZ235 was assessed by the migration assay. It was performed on a double chamber transwell as previously described. ${ }^{17}$ Briefly, 
H1975 cells were seeded into 24-well plates and incubated with different concentrations of drugs. Dispersed by trypsin, $2 \times 10^{5}$ cells were seeded into the upper chamber in triplicate. Then, fresh medium containing 30\% fetal bovine serum was added to the lower chamber. After incubation at $37^{\circ} \mathrm{C}$ for 24 hours, migrated cells were stained and counted in five randomly-selected fields.

\section{Western blot analysis}

To detect the levels of proteins involved in the PI3K/AKT/ mTOR signaling pathway, Western blotting was performed. H1975 cells were treated with BEZ235 or gefitinib for 16 hours and whole cell extracts were prepared as described previously. ${ }^{18}$ Equal amounts of proteins were separated on SDS-PAGE $8 \%-15 \%$ Bis-Tris gel and transferred to a polyvinylidene difluoride membrane (EMD Millipore, Billerica, MA, USA). The membrane was then probed with the aforementioned primary antibodies respectively, and protein expression was visualized by using the ECL and the results were transferred to the photographic film.

\section{Xenograft models of HI975 cell lines in $\mathrm{BALB} / \mathrm{c}$ nude mice}

Thirty-two male 6-week old BALB/c nude mice, weighing from 18 to $20 \mathrm{~g}$, were obtained from Hubei Experimental Animal Research Center, People's Republic of China. The animals were raised under the specific pathogen-free conditions in the Experimental Animal Center of Huazhong University of Science and Technology, Wuhan, People's Republic of China. They were divided into four groups $(\mathrm{n}=8)$ and were subcutaneously implanted with H1975 cells $\left(1 \times 10^{7} / 0.2 \mathrm{~mL}\right.$ in each nude mouse). The length and width of the tumors were measured every other day following the first day of H1975 cells' implantation. When the tumor volume reached $280 \mathrm{~mm}^{3}$ (tumor volume was calculated as follows: tumor volume $=$ length $\times$ width $^{2} \times \pi / 6$ ), the mice were divided into four groups and drugs were administered: a blank control group, a GEF group (gefitinib at $60 \mathrm{mg} / \mathrm{kg}$ orally every other day), a BEZ group (BEZ235 at $40 \mathrm{mg} / \mathrm{kg}$ subcutaneous injection every other day), and a group with a combination of gefitinib and BEZ235. Two weeks after the drug administration, the mice were sacrificed and tumors were excised. The weight and volume of the tumors were measured, and cluster of differentiation (CD)31 and vascular endothelial growth factor (VEGF) were immunohistochemically determined. All animal experiments were performed with the approval of the institutional animal use and care committee.

\section{Statistical analysis}

The data were expressed as mean \pm standard deviation from independent experiments. Statistical significance was evaluated by using the Student's $t$-test. The level of significance was set at $P<0.05$. Origin 7.5 was used for plotting the data.

\section{Results}

\section{Resistance of HI975 cell line to gefitinib and presence of secondary mutation of EGFR}

To understand whether the H1975 cell line is an ideal model of gefitinib resistance, we assessed the cellular proliferation by MTT assay, and amplification of the EGFR exons 18-21 in the H1975 cell line. After incubation with gefitinib for 72 hours, as shown in Figure 1A, H1975 cell growth was not inhibited until the concentration of gefitinib was over $3 \mu \mathrm{mol} / \mathrm{L}$ $(P<0.05)$. The $\mathrm{IC}_{50}$ was $22.61 \mu \mathrm{mol} / \mathrm{L}$, which was consistent with the result of a previous report. ${ }^{8}$ It has been reported previously that the H1975 cell line carries L858R-T790M EGFR mutation and is resistant to gefitinib and erlotinib. 6,19 To confirm the secondary T790M mutation in the H1975 cell line, polymerase chain reaction was performed to amplify the exons $18-21$ of EGFR. The nucleotide sequencing exhibited that there existed a C-to-T point mutation in exon 20, which was due to the threonine-to-methionine substitution at codon 790 (T790M). Another T-to-G point mutation in exon 18, which led to arginine being substituted by leucine at codon 858 (L858R) was also observed (Figure 1B).

\section{Inhibition of HI975 cell growth by NVP-BEZ235 alone or in combination with gefitinib}

After H1975 cells were incubated for 72 hours with an increasing concentration of BEZ235 alone or in combination with gefitinib, H1975 cell growth was strongly inhibited when BEZ235 concentration was more than $0.1 \mu \mathrm{mol} / \mathrm{L}(P<0.05)$, as shown in Figure 1A. The $\mathrm{IC}_{50}$ of BEZ235 alone was $0.151 \mu \mathrm{mol} / \mathrm{L}$. When BEZ235 was given with gefitinib, the cell growth was suppressed at a higher inhibition ratio compared to the treatment with BEZ235 alone. The $\mathrm{IC}_{50}$ of gefitinib and BEZ235 were $0.177 \mu \mathrm{mol} / \mathrm{L}$ and $0.056 \mu \mathrm{mol} / \mathrm{L}$ respectively. The calculated combination index was 0.378 , which indicated a strong synergistic effect of these two compounds.

\section{Inhibition of HI975 cell migration by NVP-BEZ235}

The inhibitory effect of BEZ235 on the migration of H1975 cells was examined by migration assay. Figure $2 \mathrm{~A}$ shows cell 


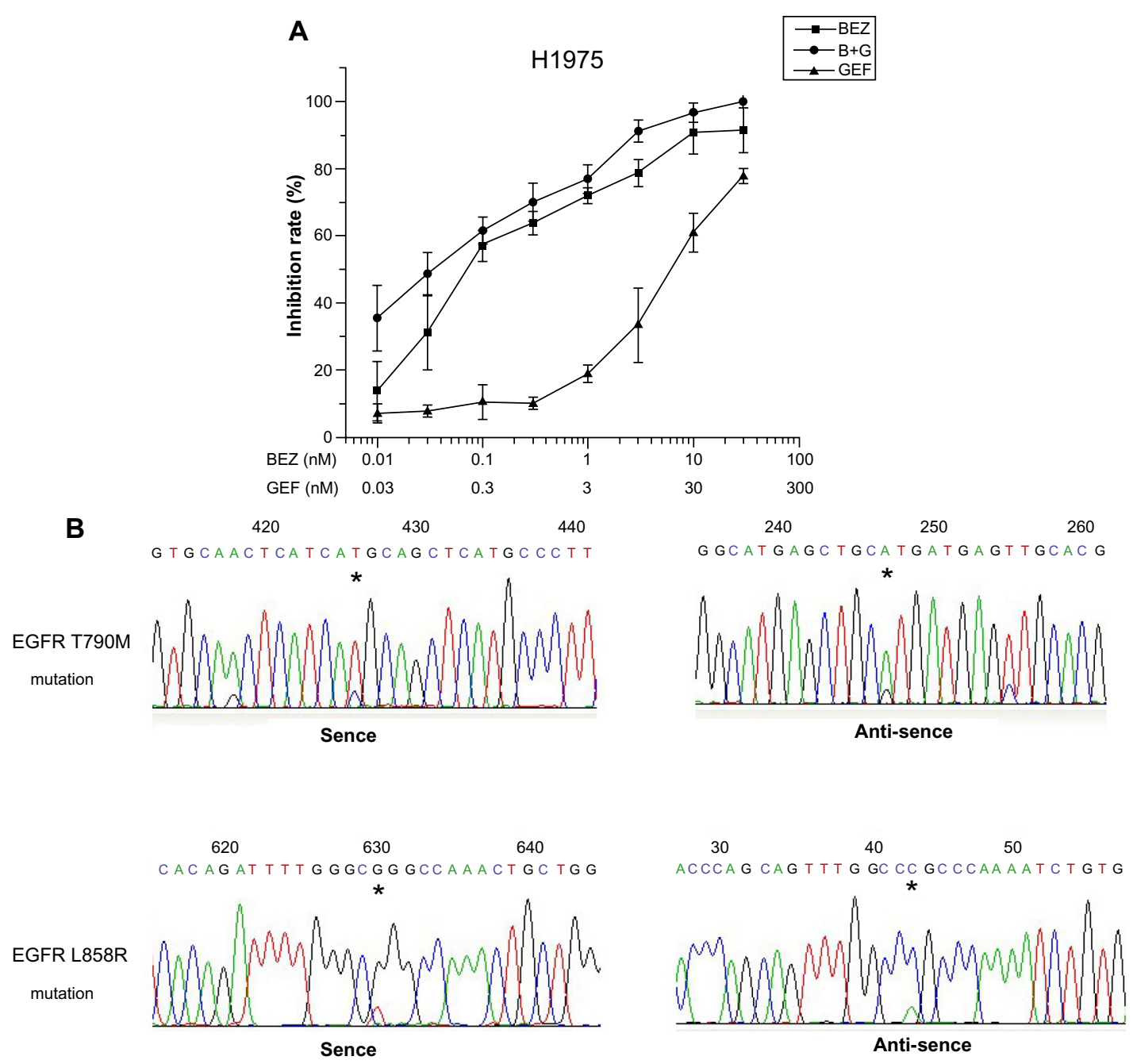

Figure I HI975 cell line was resistant to gefitinib and inhibited by BEZ235.

Notes: (A) HI 975 cells were treated with different concentrations of BEZ235 as well as with combinations with gefitinib. After 3 days, viable cell numbers were estimated by MTT assay. Mean values of three independent measurements ( \pm SD) are shown. (B) We extracted HI 975 cells' DNA, and then polymerase chain reaction was used to amplify the exons I8-2I of EGFR; the products were directly sequenced in both sense and antisense directions by Invitrogen. *indicates the the site of base change in the mutation. Abbreviations: B+G, NVP-BEZ235 combination with gefitinib; BEZ, NVP-BEZ235; EGFR, epidermal growth factor receptor; GEF, gefitinib; L858R, leucine-to-arginine substitution at codon 858; MTT, 3-(4,5-Dimethylthiazol-2-yl)-2,5-diphenyltetrazolium bromide; SD, standard deviation; T790M, threonine-to-methionine substitution at codon 790 .

migration was significantly inhibited by BEZ235 alone. The difference of the inhibitory effect between each group suggested that the inhibition acts in a dose-dependent manner. When administrated and combined with gefitinib, BEZ235 inhibited H1975 cell migration in the same manner, as seen in Figure 2B.

\section{Inhibitory effect of NVP-BEZ235 on the growth of HI975 xenografts in nude mice}

In view of the in vitro growth-inhibiting effects of BEZ235 on H1975 cells, we verified its in vivo inhibitory action in nude mice. The mice were randomized into four groups with similar average tumor volume (Figure 3A). As expected, the tumor volume was decreased two weeks after BEZ235 administration. At the end of treatment, the average tumor volume of the blank group was $1973.22 \pm 156.04 \mathrm{~mm}^{3}$, while the average tumor volume of BEZ235 group was $1198.76 \pm 123.28 \mathrm{~mm}^{3}$ and $379.92 \pm 54.74 \mathrm{~mm}^{3}$ for the combination group, respectively. The tumor volumes of BEZ235 alone and the combination groups were significantly different from that of the blank group $(P<0.05)$. These in vivo findings further demonstrated that BEZ235 significantly inhibited the growth of H1975 xenografts (Figure 3B and C).

\section{Inhibition of PI3K/AKT/mTOR signaling pathway by NVP-BEZ235 via reducing phosphorylation in vitro and in vivo}

To understand the mechanisms by which BEZ235 inhibits gefitinib-resistant NSCLC, we examined the effects of 

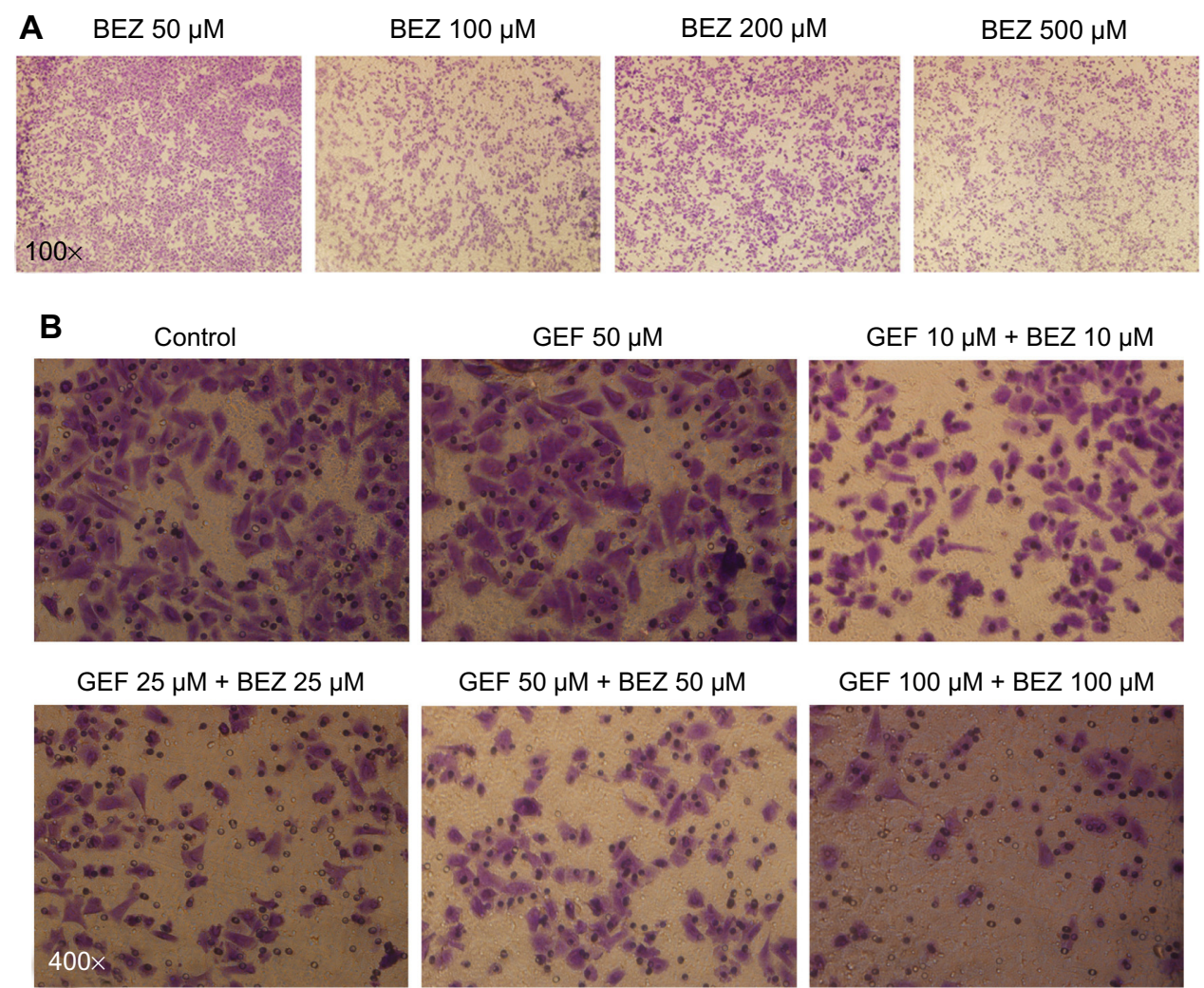

GEF $50 \mu \mathrm{M}+\mathrm{BEZ} 50 \mu \mathrm{M}$
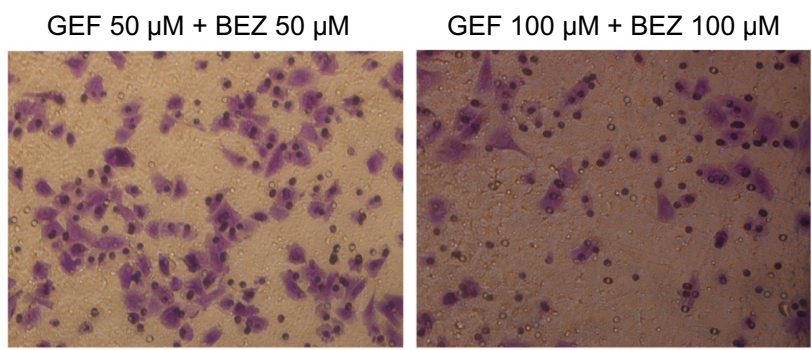

Figure 2 HI 975 cell migration was inhibited by BEZ235.

Notes: HI 975 cells were seeded in 24-well plates and incubated with different concentrations of drugs. After 24 hours incubation, migrated cells were stained. The results are from a representative experiment. Each experiment, repeated three times, yielded similar results. (A) The inhibitory effect of BEZ235 on HI 975 cells' migration was increased with BEZ235 concentration. (B) HI975 cells migration was inhibited by combined administration of BEZ235 and gefitinib.

Abbreviations: BEZ, NVP-BEZ235; GEF, gefitinib.

BEZ235 on the expression of crucial proteins of PI3K/ AKT/mTOR signaling pathway both in vitro and in vivo. The doses of drugs (BEZ235 at $200 \mathrm{nM}$ and gefitinib at $0.1 \mu \mathrm{mol} / \mathrm{L}$ ) in the four groups (DMSO control, $0.1 \mu \mathrm{mol} / \mathrm{L}$ gefitinib, $200 \mathrm{nmol} / \mathrm{L}$ BEZ235 and combination use of gefitinib and BEZ235) were similar to the concentrations used in previous studies. ${ }^{14,20,21}$ With the in vitro study, H1975 cells were incubated in the presence of different components for 16 hours. We observed that the total protein AKT and S6 expression was not significantly altered by any treatment. However, the level of the phosphorylated proteins, Ser473p-AKT and Ser235/236-p-S6, were decreased in the presence of BEZ235 and the combination of two drugs, while gefitinib did not cause any change in the expression of phosphorylated proteins (Figure 4A). Similar results were confirmed by the protein analysis of the tumor xenografts as shown in Figure 4B.

\section{Inhibitory effect of NVP-BEZ235 in combination with gefitinib on VEGF and CD3 I expression}

Aberrant PI3K signaling impairs phosphatase and tensin homologue function, which plays an important part in tumor angiogenesis and in normal vascular formation. ${ }^{22,23}$ Therefore, we examined whether BEZ235 could interfere with tumor angiogenesis in nude mice xenografts. Immunohistochemical detection showed a significant reduction in VEGF and CD31 staining in BEZ235-treated tumors as compared with the controls (Figure 5), suggesting that BEZ235 may be involved in the inhibition of tumor angiogenesis.

\section{Discussion}

Development of acquired resistance is crucial for the treatment of NSCLC with EGFR TKI because of its high initial response rate. ${ }^{24}$ Secondary mutation of EGFR, including T790M and proto-oncogene MET amplification, have been reported as the two most important mechanisms responsible for gefitinib acquired resistance. ${ }^{7,9}$ These two even share a common consequence: aberrant activation of the PI3K/AKT/ mTOR signaling pathway.

$\mathrm{PI} 3 \mathrm{~K}$ is a pivotal kinase involved in the transmission of signals, and the correlation of aberrant PI3K signaling with cancer development has long been confirmed. ${ }^{25-28}$ In cancers, PI3K activation is frequently over-stimulated by amplification $^{29}$ and/or mutations ${ }^{30}$ of the PI3KCA gene, as well as by functional deficiency of the phosphatase and tensin 
A

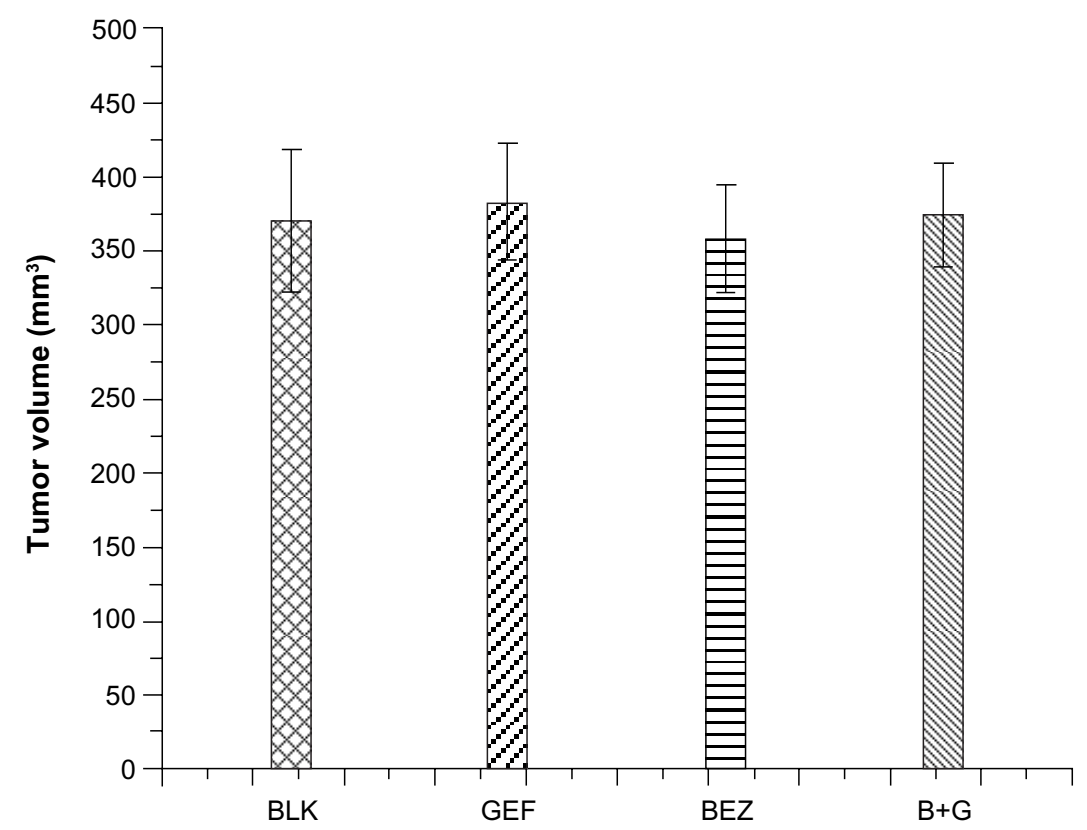

\section{B}

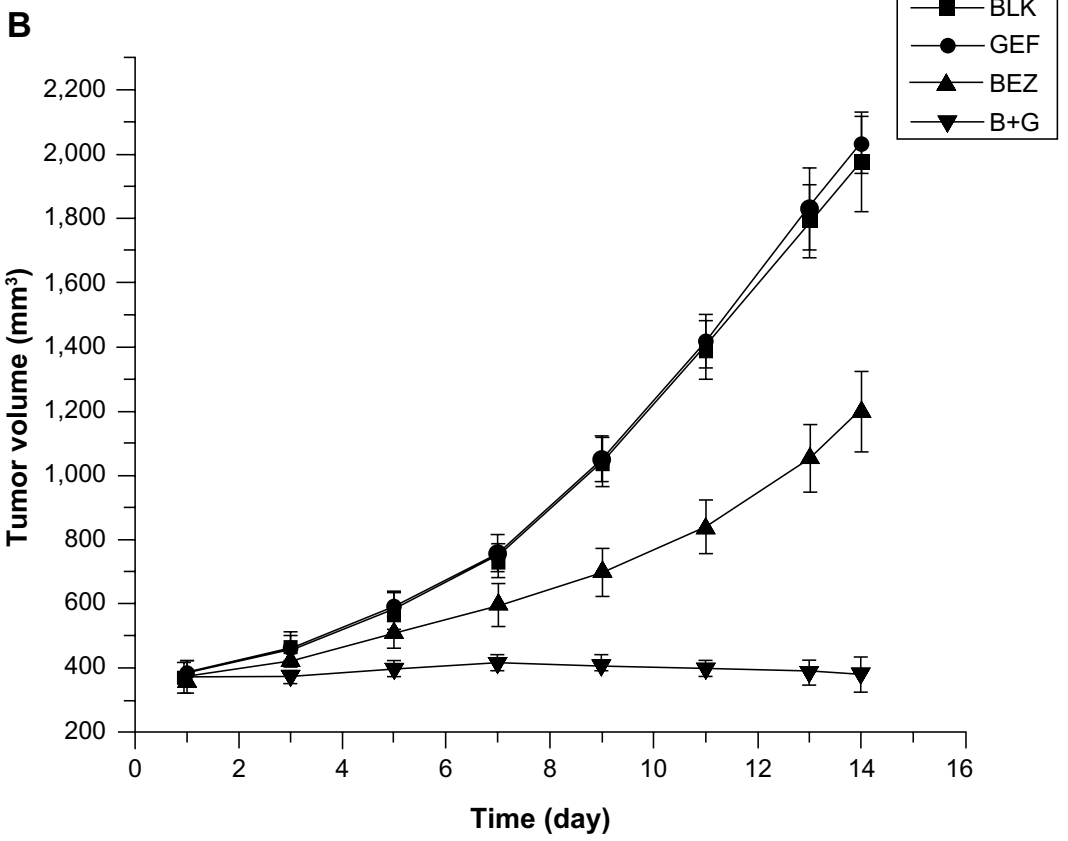

C BLK
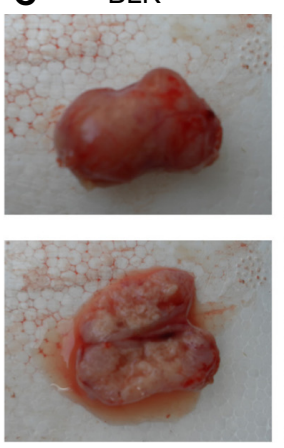

GEF
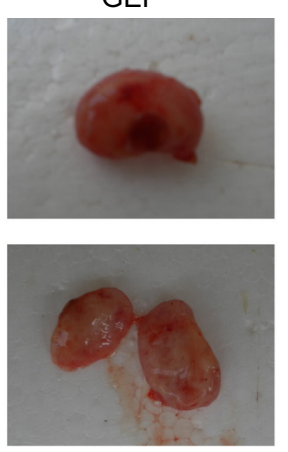

BEZ
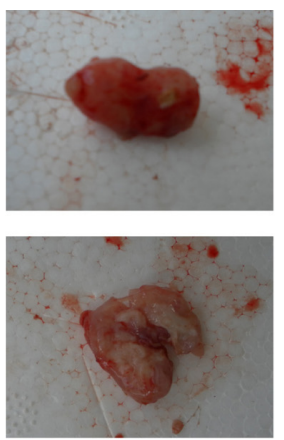

$B+G$
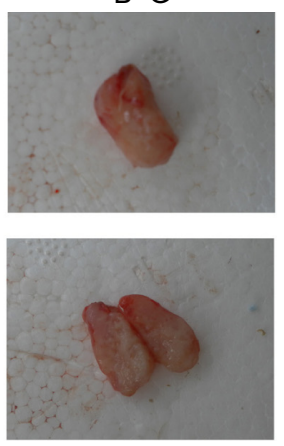

Figure 3 HI975 cells were implanted into nude mice. (A) The tumor volume did not show significant difference, before treatment with different components. (B) The tumor volumes started to show differences with different components' treatment. (C) The observation of tumors after 2 weeks of different components' treatment.

Abbreviations: B+G, NVP-BEZ235 combination with gefitinib; BEZ, NVP-BEZ235; BLK, blank control; GEF, gefitinib. 

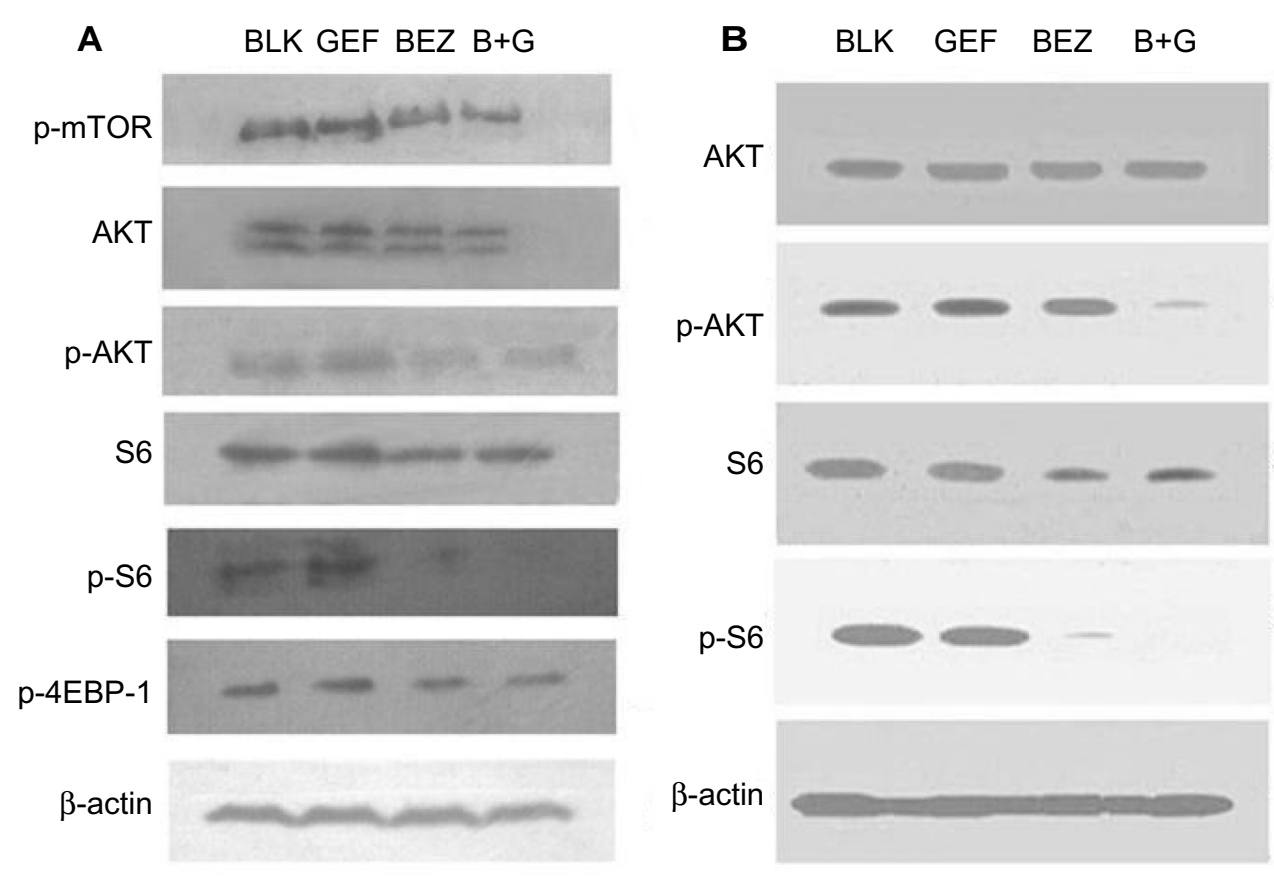

Figure 4 Analysis of PI3K/AKT/mTOR signaling pathway protein.

Notes: After treatment with BEZ235 or gefitinib, cells or xenografts' tissue were then lysed and Western blot was performed. (A) The protein expression of the in vitro study and $(\mathbf{B})$ the in vivo study. Results are from representative experiments. Each experiment, repeated three times, yielded similar results.

Abbreviations: AKT, protein kinase B; B+G, NVP-BEZ235 combination with gefitinib; BLK, blank control; BEZ, NVP-BEZ235; GEF, gefitinib; mTOR, mammalian target of rapamycin; 4EBP-I, 4E binding protein I; PI3K, phosphoinositide 3-kinase; p, phosphorylated.

homologue, an important tumor suppressor gene. ${ }^{31}$ These studies have identified PI3K as an attractive therapeutic target for cancer treatment. BEZ235 is a potent and reversible adenosine triphosphatase competitor that inhibits p110 of PI3K and mTOR and suppresses several downstream effectors of the PI3K pathway. ${ }^{13}$

Isolated from a non-smoking female patient suffering from lung adenocarcinoma, H1975 cell line harbors EGFR T790M and L858R mutations, and has been used as a gefitinib-resistant cell model. ${ }^{19}$

Our in vitro study demonstrated that BEZ235 effectively inhibited the growth of H1975 cells. In vivo BEZ235 treatment of nude mice xenografts showed that the tumors' size decreased significantly. In addition, BEZ235 inhibited H1975 cells migration in a dose-dependent manner. Taken together, these results suggest that BEZ235 might be an effective alternative for the treatment of NSCLC resistant to gefitinib.

To understand the underlying mechanism of growth inhibition induced by BEZ235 in gefitinib- resistant NSCLC, we examined the protein levels of the PI3K/AKT/mTOR signaling pathway after drug treatment. Both in vitro and in vivo studies demonstrated that administration of the BEZ235 resulted in phosphorylated proteins' reduction. Thus, we were led to speculate that down-regulation of pAKT and pS6 is one of the mechanisms by which BEZ235 inhibits the proliferation of H1975 cells. These findings were in agreement with
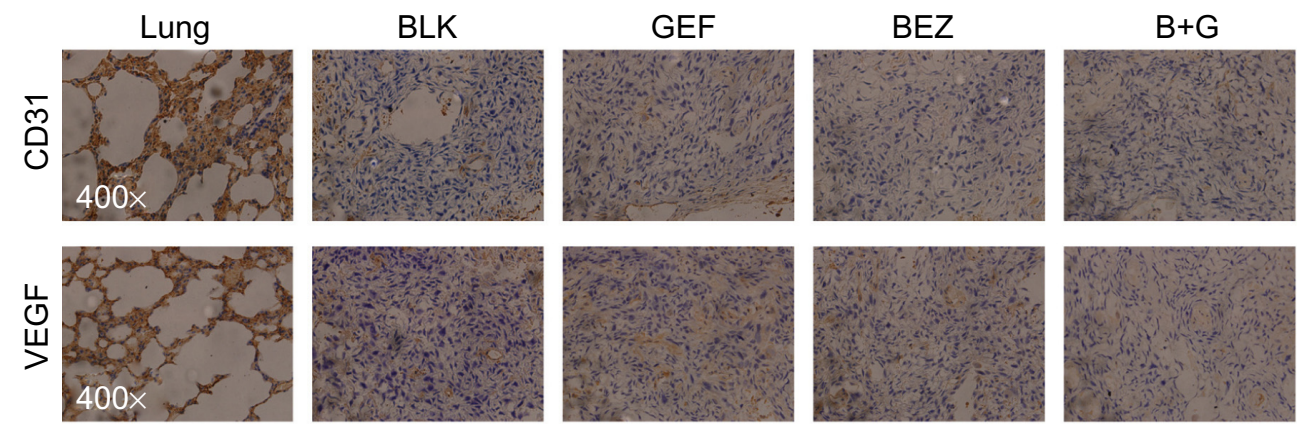

Figure 5 BEZ235 combination with gefitinib reduced VEGF and CD3I expression in vivo.

Note: Immunohistochemistry of CD3I and VEGF was performed for tumors treated with gefitinib, BEZ235, and their combination.

Abbreviations: B+G, NVP-BEZ235 combination with gefitinib; BEZ, NVP-BEZ235; BLK, blank control; CD, cluster of differentiation; GEF, gefitinib; VEGF, vascular endothelial growth factor. 
previous studies which demonstrated that the inhibition of cell growth by BEZ235 is associated with PI3K/AKT/mTOR phosphorylation. ${ }^{17,21,32,33}$

Gefitinib has been reported to decrease VEGF expression in squamous cell carcinoma cells in either a hypoxiainducible factor (HIF-1)-dependent or HIF-1-independent manner. ${ }^{34}$ Furthermore, the HIF- $1 \alpha$ has also been confirmed to be a downstream factor of the mTOR signaling pathway, ${ }^{35}$ suggesting that the EGFR/PI3K/AKT/mTOR signal axis regulates VEGF expression and thereby tumor angiogenesis. Consistent with the finding of studies with different malignancies, BEZ235 induced a significantly reduced VEGF expression in xenograft animal models. ${ }^{16,36,37}$ Parallel results were observed for CD31, a biomarker that has been used to measure microvessel density in tumor tissues.

In summary, the present study has demonstrated that BEZ235 specifically inhibited the growth of gefitinibresistant tumors, both in cellular models and in xenografts. Further evidence showed that this growth inhibition was associated with the PI3K/AKT/mTOR phosphorylation. Our study provided a foundation for the further clinical use of BEZ235 in the treatment of gefitinib-resistant tumors.

\section{Acknowledgments}

This study was supported by Wu Jieping medical foundation, Beijing, People's Republic of China (No 320.6700.09069). We are indebted to AstraZeneca for kindly supplying gefitinib, and to Meera Dassarath for her assistance in the preparation of the manuscript.

\section{Disclosure}

The authors have no conflicts of interest in this work.

\section{References}

1. Siegel R, Naishadham D, Jemal A. Cancer statistics, 2012. CA Cancer J Clin. 2012;62(1):10-29.

2. Sharma SV, Bell DW, Settleman J, Haber DA. Epidermal growth factor receptor mutations in lung cancer. Nat Rev Cancer. 2007;7(3): 169-181.

3. Lynch TJ, Bell DW, Sordella R, et al. Activating mutations in the epidermal growth factor receptor underlying responsiveness of non-small-cell lung cancer to gefitinib. $N$ Engl J Med. 2004;350(21):2129-2139.

4. Gazdar AF. Activating and resistance mutations of EGFR in non-smallcell lung cancer: role in clinical response to EGFR tyrosine kinase inhibitors. Oncogene. 2009;28 Suppl 1:S24-S31.

5. Engelman JA, Settleman J. Acquired resistance to tyrosine kinase inhibitors during cancer therapy. Curr Opin Genet Dev. 2008;18(1):73-79.

6. Pao W, Miller VA, Politi KA, et al. Acquired resistance of lung adenocarcinomas to gefitinib or erlotinib is associated with a second mutation in the EGFR kinase domain. PLoS Med. 2005;2(3):e73.

7. Kobayashi S, Boggon TJ, Dayaram T, et al. EGFR mutation and resistance of non-small-cell lung cancer to Gefitinib. $N$ Engl J Med. 2005;352(8):786-792.
8. Kubo T, Yamamoto H, Lockwood WW, et al. MET gene amplification or EGFR mutation activate MET in lung cancers untreated with EGFR tyrosine kinase inhibitors. Int J Cancer. 2009;124(8):1778-1784.

9. Bean J, Brennan C, Shih JY, et al. MET amplification occurs with or without T790M mutations in EGFR mutant lung tumors with acquired resistance to gefitinib or erlotinib. Proc Natl Acad Sci U SA. 2007;104(52):20932-20937.

10. Engelman JA, Zejnullahu K, Mitsudomi T, et al. MET amplification leads to gefitinib resistance in lung cancer by activating ERBB3 signaling. Science. 2007;316(5827):1039-1043.

11. Vivanco 1, Sawyers CL. The phosphatidylinositol 3-Kinase-AKT pathway in human cancer. Nat Rev Cancer. 2002;2(7):489-501.

12. Sarbassov DD, Guertin DA, Ali SM, Sabatini DM. Phosphorylation and regulation of Akt/PKB by the rictor-mTOR complex. Science. 2005;307(5712):1098-1101.

13. Engelman JA, Luo J, Cantley LC. The evolution of phosphatidylinositol 3-kinases as regulators of growth and metabolism. Nat Rev Genet. 2006;7(8):606-619.

14. Maira SM, Stauffer F, Brueggen J, et al. Identification and characterization of NVP-BEZ235, a new orally available dual phosphatidylinositol 3-kinase/mammalian target of rapamycin inhibitor with potent in vivo antitumor activity. Mol Cancer Ther. 2008;7(7):1851-1863.

15. Baumann P, Mandl-Weber S, Oduncu F, Schmidmaier R. The novel orally bioavailable inhibitor of phosphoinositol-3-kinase and mammalian target of rapamycin, NVP-BEZ235, inhibits growth and proliferation in multiple myeloma. Exp Cell Res. 2009;315(3):485-497.

16. Liu TJ, Koul D, LaFortune T, et al. NVP-BEZ235, a novel dual phosphatidylinositol 3-kinase/mammalian target of rapamycin inhibitor, elicits multifaceted antitumor activities in human gliomas. Mol Cancer Ther. 2009;8(8):2204-2210.

17. Zito CR, Jilaveanu LB, Anagnostou V, et al. Multi-level targeting of the phosphatidylinositol-3-kinase pathway in non-small cell lung cancer cells. PLoS One. 2012;7(2):e31331.

18. Sliva D, Labarrere C, Slivova V, Sedlak M, Lloyd FP Jr, Ho NW. Ganoderma lucidum suppresses motility of highly invasive breast and prostate cancer cells. Biochem Biophys Res Commun. 2002;298(4): 603-612.

19. Kobayashi S, Ji H, Yuza Y, et al. An alternative inhibitor overcomes resistance caused by a mutation of the epidermal growth factor receptor. Cancer Res. 2005;65(16):7096-7101.

20. Faber AC, Li D, Song Y, et al. Differential induction of apoptosis in HER2 and EGFR addicted cancers following PI3K inhibition. Proc Natl Acad Sci U S A. 2009;106(46):19503-19508.

21. Serra V, Markman B, Scaltriti M, et al. NVP-BEZ235, a dual $\mathrm{PI} 3 \mathrm{~K} / \mathrm{m}$ TOR inhibitor, prevents PI3K signaling and inhibits the growth of cancer cells with activating PI3K mutations. Cancer Res. 2008;68(19):8022-8030.

22. Daido S, Kanzawa T, Yamamoto A, Takeuchi H, Kondo Y, Kondo S. Pivotal role of the cell death factor BNIP3 in ceramideinduced autophagic cell death in malignant glioma cells. Cancer Res. 2004;64(12):4286-4293.

23. Hamada K, Sasaki T, Koni PA, et al. The PTEN/PI3K pathway governs normal vascular development and tumor angiogenesis. Genes Dev. 2005;19(17):2054-2065.

24. Costa DB, Kobayashi S, Tenen DG, Huberman MS. Pooled analysis of the prospective trials of gefitinib monotherapy for EGFR-mutant non-small cell lung cancers. Lung Cancer. 2007;58(1):95-103.

25. Ertmer A, Huber V, Gilch S, et al. The anticancer drug imatinib induces cellular autophagy. Leukemia. 2007;21(5):936-942.

26. Vogt PK, Bader AG, Kang S. Phosphoinositide 3-kinase: from viral oncoprotein to drug target. Virology. 2006;344(1):131-138.

27. Workman P, Clarke PA, Raynaud FI, van Montfort RL. Drugging the PI3 kinome: from chemical tools to drugs in the clinic. Cancer Res. 2010;70(6):2146-2157.

28. Workman P, Clarke PA, Guillard S, Raynaud FI. Drugging the PI3 kinome. Nat Biotechnol. 2006;24(7):794-796. 
29. Sugawa N, Ekstrand AJ, James CD, Collins VP. Identical splicing of aberrant epidermal growth factor receptor transcripts from amplified rearranged genes in human glioblastomas. Proc Natl Acad Sci U S A. 1990;87(21):8602-8606.

30. Gallia GL, Rand V, Siu IM, et al. PIK3CA gene mutations in pediatric and adult glioblastoma multiforme. Mol Cancer Res. 2006;4(10):709-714.

31. Li J, Yen C, Liaw D, et al. PTEN, a putative protein tyrosine phosphatase gene mutated in human brain, breast, and prostate cancer. Science. 1997;275(5308):1943-1947.

32. Xu CX, Li Y, Yue P, et al. The combination of RAD001 and NVP-BEZ235 exerts synergistic anticancer activity against non-small cell lung cancer in vitro and in vivo. PLoS One. 2011;6(6):e20899.

33. Brünner-Kubath C, Shabbir W, Saferding V, et al. The PI3 kinase/ mTOR blocker NVP-BEZ235 overrides resistance against irreversible ErbB inhibitors in breast cancer cells. Breast Cancer Res Treat. 2011;129(2):387-400.
34. Pore N, Jiang Z, Gupta A, Cerniglia G, Kao GD, Maity A. EGFR tyrosine kinase inhibitors decrease VEGF expression by both hypoxia-inducible factor (HIF)-1-independent and HIF-1-dependent mechanisms. Cancer Res. 2006;66(6):3197-3204.

35. Hudson CC, Liu M, Chiang GG, et al. Regulation of hypoxia-inducible factor 1alpha expression and function by the mammalian target of rapamycin. Mol Cell Biol. 2002;22(20):7004-7014.

36. Roper J, Richardson MP, Wang WV, et al. The dual PI3K/mTOR inhibitor NVP-BEZ235 induces tumor regression in a genetically engineered mouse model of PIK3CA wild-type colorectal cancer. PLoS One. 2011;6(9):e25132.

37. Schnell CR, Stauffer F, Allegrini PR, et al. Effects of the dual phosphatidylinositol 3-kinase/mammalian target of rapamycin inhibitor NVP-BEZ235 on the tumor vasculature: implications for clinical imaging. Cancer Res. 2008;68(16):6598-6607.

\section{Publish your work in this journal}

OncoTargets and Therapy is an international, peer-reviewed, open access journal focusing on the pathological basis of all cancers, potential targets for therapy and treatment protocols employed to improve the management of cancer patients. The journal also focuses on the impact of management programs and new therapeutic agents and protocols on

\section{Dovepress}

patient perspectives such as quality of life, adherence and satisfaction The manuscript management system is completely online and includes a very quick and fair peer-review system, which is all easy to use. Visit http://www.dovepress.com/testimonials.php to read real quotes from published authors. 